\title{
Preserved Serotonergic Activity in Early-Onset Parkinson's Disease
}

\author{
Hee Kyung Park@i, Jae-Jung Lee, Young-Min Park
}

\begin{abstract}
Background: Serotonergic dysfunction may play an important role in motor and nonmotor symptoms of Parkinson's disease (PD). The loudness dependence of auditory evoked potentials (LDAEP) has been used to evaluate serotonergic activity. Therefore, this study aimed to determine central serotonergic activity using LDAEP in de novo PD according to the age at onset and changes in serotonergic activity after dopaminergic treatment. Methods: A total of 30 patients with unmedicated PD, 16 in the early-onset and 14 in the late-onset groups, were enrolled. All subjects underwent comprehensive neurological examination, laboratory tests, the Unified Parkinson's Disease Rating Scale, and LDAEP. The LDAEP was calculated as the slope of the two N1/P2 peaks measured at the $\mathrm{Cz}$ electrode, first at baseline conditions (pretreatment) and a second time after 12 weeks (post-treatment) following dopaminergic medications. Results: The absolute values of pretreatment N1/P2 LDAEP (early-onset: late-onset, $0.99 \pm 0.68: 1.62 \pm 0.88, p=0.035$ ) and post-treatment N1 LDAEP (early-onset: late-onset, $-0.61 \pm 0.61:-1.26 \pm 0.91, p=0.03$ ) were significantly lower in the early-onset group compared with those of the late-onset group. In addition, a higher value of pretreatment N1/P2 LDAEP was significantly correlated with the late-onset group (coefficient $=1.204, p=0.044$ ). The absolute value of the N1 LDAEP decreased after 12 weeks of taking dopaminergic medication (pretreatment: post-treatment, $-1.457 \pm 1.078$ : $-0.904 \pm 0.812, p=0.0018$ ). Conclusions: Based on the results of this study, LDAEP could be a marker for serotonergic neurotransmission in PD. Central serotonergic activity assessed by LDAEP may be more preserved in early-onset PD patients and can be altered with dopaminergic medication.
\end{abstract}

RÉSUMÉ: Préservation de l'activité sérotoninergique dans des cas précoces de maladie de Parkinson. Contexte: Il est possible que les dysfonctions de l'activité sérotoninergique jouent un rôle important dans l'apparition des symptômes moteurs et non-moteurs de la maladie de Parkinson (MP). Pour évaluer cette activité, il est possible de faire appel au marqueur visant à mesurer la « dépendance à l'intensité sonore » liée à des potentiels évoqués auditifs (PEA) (loudness dependence of the auditory evoked potentials). En cela, le but de cette étude est de déterminer, au moyen de ce marqueur, l'activité sérotoninergique centrale de patients nouvellement atteints de MP. Pour ce faire, nous décidé de tenir compte de leur âge au moment où la maladie s'est déclarée et des changements à leur activité sérotoninergique après avoir amorcé un traitement dopaminergique. Méthodes: Un total de 30 patients atteints de MP et ne suivant aucun traitement médicamenteux ont été inclus dans cette étude. De ce nombre, 16 d'entre eux en étaient à une phase précoce de la maladie alors que les autres en étaient à une phase plus tardive. Tous les participants ont subi un examen neurologique complet en plus de passer des tests de laboratoire et d'être évalués en fonction de la Unified Parkinson's Disease Rating Scale (UPDRS) et du marqueur évoqué ci-haut. Ce dernier a été calculé en fonction de la pente entre les deux sommets N1/P2 telle que mesurée au niveau de l'électrode Cz. Cela s'est fait dans un premier temps avant l'amorce d'un traitement dopaminergique et au bout de 12 semaines une fois le traitement cessé. Résultats: Les valeurs absolues N1/P2 associées à notre marqueur pendant le traitement (phase précoce : 0,99 $\pm 0,68 ;$ phase tardive : 1,62 $\pm 0,88$; $p=0,035$ ) et à notre marqueur une fois le traitement terminé (phase précoce : $-0,61 \pm 0,61 ;$ phase tardive $:-1,26 \pm 0,91 ; p=0,03$ ) se sont révélées nettement moins élevées dans le cas des 16 patients dont la MP en était à une phase précoce. De plus, des valeurs absolues N1/P2 plus élevées avant traitement ont été fortement corrélées au groupe de 14 patients dont la MP en était à une phase tardive (coefficient $=1,204, p=0,044$ ). Finalement, la valeur absolue N1/P2 associée à notre marqueur a diminué au bout de 12 semaines de traitement dopaminergique (prétraitement : $-1,457 \pm 1,078$; post-traitement : $-0,904 \pm 0,812 ; p=0,0018$ ). Conclusions: À la lumière des résultats de cette étude, nous pensons que le marqueur visant à mesurer la « dépendance à l'intensité sonore » liée à des PEA pourrait permettre de détecter la neurotransmission sérotoninergique dans le cas de la MP. Il se pourrait aussi que l'activité sérotoninergique centrale telle que mesurée par ce marqueur soit davantage préservée chez des patients qui en sont à une phase précoce de la MP et puisse être modifiée grâce à un traitement dopaminergique.

Keywords: Parkinson's disease, Serotonin, Age of onset, Loudness dependence of auditory evoked potentials, Dopamine doi:10.1017/cjn.2019.322

Can J Neurol Sci. 2020; 47: 344-349

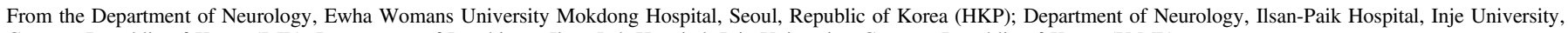
Goyang, Republic of Korea (J-JL); Department of Psychiatry, Ilsan-Pak Hospital, Inje University, Goyang, Republic of Korea (Y-MP)

Received August 23, 2019. Final Revisions Submitted October 6, 2019. Date of Acceptance October 27, 2019.

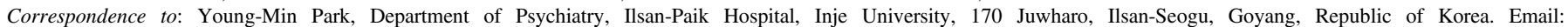
medipark@hanmail.net 


\section{INTRODUCTION}

Parkinson's disease (PD) is characterized by prominent motor and various nonmotor symptoms associated with dopamine and other neurotransmitter dysfunctions. Motor symptoms such as asymmetric resting tremor, bradykinesia, rigidity, and responsiveness to dopaminergic agents are important clues to diagnose PD in clinical practice. Nigrostriatal dopaminergic system degeneration is known to be the main cause of clinical motor symptoms in PD. However, serotonergic dysfunctions are also associated with motor and nonmotor symptoms in PD, such as levodopa-induced dyskinesia (LID), depression, sleep disturbance, and fatigue. ${ }^{1}$ Its degeneration in PD has been found in previous animal, pathological, and neuroimaging studies, ${ }^{1}$ along with a 56\% loss of serotonergic neurons in the median raphe nuclei ${ }^{2}$ and presence of Lewy neurites and Lewy bodies in the raphe nucleus at Braak stage $2 .{ }^{3}{ }^{11} \mathrm{C}$-3-amino-4-(2dimethylaminomethylphenylsulfanyl)-benzonitrile $\left({ }^{11} \mathrm{C}\right.$-DASB) positron emission tomography (PET) investigation of presynaptic serotonergic terminal function showed a reduced uptake in the striatum and extrastriatal areas. ${ }^{4}$ A reduction of serotonergic terminals was found to be correlated with disease duration. ${ }^{5}$ However, few studies have evaluated the differences in serotonergic activity according to age of onset and change in serotonergic activity after dopaminergic treatments.

The loudness dependence of auditory evoked potentials (LDAEP) is calculated using the amplitude of event-related potentials, such as N100 and P200 elicited by auditory stimuli (Figure 1). This has been used to evaluate central serotonergic activity in psychiatric disorders and $\mathrm{PD} .^{6-8}$ It assumes that the serotonergic innervation is high in the primary auditory cortex. ${ }^{9}$ Therefore, the LDAEP of a vertically oriented dipole, reflecting about $80 \%$ of activity of the primary auditory cortex, can be measured as the slope of the amplitude/loudness function in the N1/P2 potentials. ${ }^{6,9}$ Clinical and animal studies have indicated that the LDAEP is a reliable marker of central serotonergic activity, although some research involving humans has produced inconsistent findings. ${ }^{10,11}$ LDAEP may be inversely correlated with central serotonergic activity. ${ }^{6,9,12}$ High serotonergic activity may be demonstrated with a low LDAEP, while low serotonergic neurotransmission may be shown with a high LDAEP. In fact, a recent study found decreased serotonergic activity as well as dopaminergic activity in the early stages of PD using LDAEP. ${ }^{8}$

If LDAEP were a useful marker for central serotonergic activity in PD, preserved serotonergic activity would be shown in early-onset PD since early-onset PD has more frequent LID than late-onset $\mathrm{PD}^{13-15}$ and LID is known to be related to preserved serotonergic activity. ${ }^{5,16}$ This study aimed to determine central serotonergic functions in unmedicated PD patients using LDAEP to measure serotonergic activity by the disease itself and to compare serotonergic activity between early-onset PD and late-onset PD. Furthermore, since we assumed that serotonergic activity might be altered with dopaminergic medications in PD, we also investigated the differences in serotonergic activity depending on the use of dopaminergic medications.

\section{Methods}

Between September 2013 and January 2017, 30 patients with unmedicated PD, diagnosed based on the UK Brain Bank criteria, ${ }^{17}$ were prospectively enrolled. Subjects with drug-induced parkinsonism, structural lesions causing parkinsonism, and serious medical illnesses were excluded from this study, along with subjects with major psychiatric disorders, including depression, diagnosed by a psychiatrist according to the Diagnostic and Statistical Manual of Mental Disorders, Fourth Edition, Text Revision (DSM-IV-TR). Only one patient had a family history of PD.

All participants were interviewed by a neurologist and underwent comprehensive neurological examination, laboratory analyses, brain magnetic resonance imaging, and LDAEP measurements. The levodopa equivalent dose was calculated. ${ }^{18}$ Disease severity was assessed using the modified Hoehn and Yahr stage (modified H\&Y stage), and motor status was evaluated using the Unified Parkinson's Disease Rating Scale (UPDRS). ${ }^{19}$ PD patients were initially divided into three groups: the young-onset group ( $\leq 49$ years, $n=3$ ), the middle-age group (50-69 years, $n=13$ ), and the late-onset group ( $\geq 70$ years, $n=14) .{ }^{15}$ However, since there were too few subjects in the young-onset group they were added to the middle-onset one, hence obtaining only two age groups: the early-onset group ( $\leq 69$ years, $n=16)$ and the lateonset group ( $\geq 70$ years, $n=14$ ).

The N1 and P2 peaks were measured at the $\mathrm{Cz}$ electrode for auditory stimuli at five intensities $(55,65,75,85,95 \mathrm{~dB}) .{ }^{20}$ The LDAEP was measured twice, at baseline (pretreatment) and 12 weeks after administering a dopaminergic medication (post-treatment). ${ }^{20}$ The LDAEP was determined by calculating the slope (the amplitude/loudness function) of the two N1/P2 peaks. Standardized low-resolution brain electromagnetic tomography (LORETA) was used to determine the current density in area BA41 (primary auditory cortex) using our previous method. $^{20}$

\section{EтHICS}

The institutional review board approved this study (IRB subject no.: 2013-9-334), and informed consents were obtained from all participants.

\section{Statistical Analysis}

The Kolmogorov-Smirnov test was used to check whether the clinical variables were normally distributed. Student's $t$-test, the Mann-Whitney $U$-test, and the $\chi^{2}$ test were used to compare clinical variables between the early- and late-onset groups as well as between male and female patients. The pretreatment and posttreatment clinical variables in PD patients were compared by paired $t$-tests or Wilcoxon's signed ranks test. Multiple binary logistic regression analysis for the relationship between age of onset and LDAEP was also conducted. All tests were two-tailed, and the cutoff for significant group differences was $p<0.05$. The statistical analysis was performed using RexSoft. ${ }^{21}$

\section{Results}

Of the 30 patients with unmedicated PD, $66.7 \%$ were male. The mean age of the study population was 68.9 years and the mean age at onset was 67.2 years (Table 1). None of the patients had depression and none took antidepressants. Smoking was reported in one patient. Right-side-dominant parkinsonism was reported in 20 patients, while left-side-dominant parkinsonism 


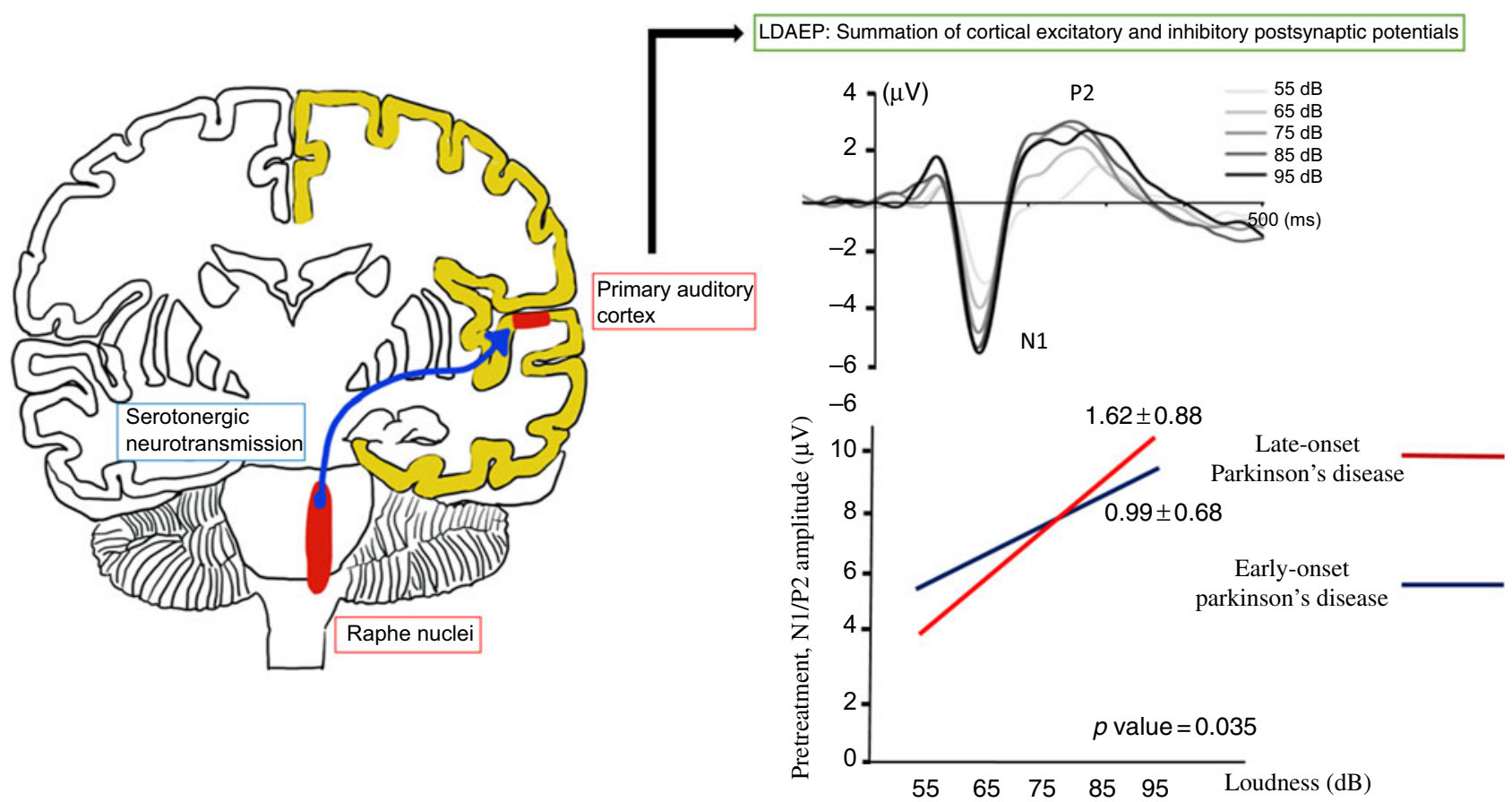

Figure 1: The loudness dependence of auditory evoked potentials (LDAEP) and the pretreatment N1/P2 LDAEP in late-onset Parkinson's disease and early-onset Parkinson's disease.

was reported in 9 patients. Table 2 shows that there were no differences in demographic variables other than age and age at onset, or in the pretreatment LDAEP (N1 and P2), post-treatment LDAEP (P2 and N1/P2), pretreatment LORETA (N1, P2, and $\mathrm{N} 1 / \mathrm{P} 2$ ), and post-treatment LORETA (N1, P2, and N1/P2) between the early-onset $(n=16)$ and late-onset $(n=14)$ groups. The absolute values of the pretreatment N1/P2 LDAEP (Figure 1) and post-treatment N1 LDAEP were significantly lower in the early-onset group than those in the late-onset group.

Demographic variables and the pretreatment LDAEP (N1, P2, and N1/P2), post-treatment LDAEP (N1, P2, and N1/P2), pretreatment LORETA (N1, P2, and N1/P2), and post-treatment LORETA (N1, P2, and N1/P2) did not differ between male and female patients. As shown in Figure 2, the post-treatment N1 LDAEP was significantly lower than the pretreatment N1 LDAEP after 12 weeks of taking a dopaminergic medication in all PD patients $(p=0.0018)$, in the early-onset group ( $p=0.047)$, and in the late-onset group $(p=0.0072)$. There were no differences in the P2 LDAEP, N1/P2 LDAEP, N1 LORETA, P2 LORETA, and N1/P2 LORETA between pretreatment and post-treatment (Table 1). In addition, in multiple binary logistic regression analysis for the early- and late-onset groups, higher pretreatment N1/P2 LDAEP was significantly related with the late-onset group $($ coefficient $=1.204, p=0.044)($ Table 3$)$.

\section{Discussion}

This study found that the absolute values of pretreatment N1/ P2 LDAEP and post-treatment N1 LDAEP were lower in the early-onset group than in the late-onset group. A higher pretreatment N1/P2 LDAEP was significantly correlated with the late-onset group. In addition, the post-treatment N1 LDAEP decreased significantly after 12 weeks of dopaminergic medications in all subjects, as well as in both the early- and late-onset groups. The smaller pretreatment N1/P2 LDAEP and post-treatment N1 LDAEP in the early-onset group suggests that central serotonergic activity was more preserved in this group than in the late-onset group. This effect was maintained after controlling for gender and disease severity (modified H\&Y stage). The smaller pretreatment N1/P2 LDAEP was also related to early-onset PD based on multiple binary logistic regression analysis. These findings confirm our hypothesis that early-onset PD might have more preserved serotonergic activity than late-onset PD. Younger-onset PD patients are more likely to have LID, ${ }^{13-15}$ a higher rate of dystonia, ${ }^{13}$ and a slower progression, ${ }^{22}$ while olderonset PD patients are associated with more severe motor and nonmotor symptoms and a higher risk of dementia. ${ }^{13,23}$ In particular, LID in PD is known to be associated with serotonergic activity, which is due to excessive dopamine release in serotonergic terminals without autoregulatory feedback of dopamine release, ${ }^{16}$ and an aberrant sprouting of serotonin terminals could play a role in the development of LID in PD. ${ }^{24} \mathrm{PD}$ patients with LID showed preserved serotonergic terminals compared to PD patients without LID in a ${ }^{11} \mathrm{C}$-DASB PET study. ${ }^{5}$ Therefore, the higher serotonergic activity in the early-onset group in the present study is in accordance with results of previous studies, suggesting that LDAEP can be a useful noninvasive marker for central serotonergic activity in PD.

The N1 LDAEP was higher at pretreatment than after levodopa treatment, suggesting that serotonergic activity could be affected by dopaminergic medications as well as a disease per se. There is a growing body of evidence from animal, biochemical, postmortem, and human studies of loss of striatal and extrastriatal serotonin markers in PD patients suggesting that the serotonergic function is affected by PD pathology. ${ }^{1,25}$ A previous study found the activation of the serotonergic system in rats with a lesioned striatum after levodopa had been infused. ${ }^{26}$ Another study found that the LDAEP decreased after levodopa treatment in patients 
Table 1: Baseline demographics, LDAEP, and LORETA of PD patients

\begin{tabular}{|c|c|}
\hline & PD patients \\
\hline Age, years & $68.9 \pm 11.1$ \\
\hline Age at onset, years & $67.2 \pm 11.7$ \\
\hline Sex, males/females & $20 / 10$ \\
\hline Modified H\&Y stage & $2.2 \pm 0.5$ \\
\hline UPDRS I & $2.0 \pm 2.8$ \\
\hline UPDRS II & $7.9 \pm 6.7$ \\
\hline UPDRS III & $31.9 \pm 13.2$ \\
\hline LED, mg (at 12 weeks) & $418.3 \pm 127.6$ \\
\hline \multicolumn{2}{|l|}{ LDAEP } \\
\hline Pretreatment $\mathrm{N} 1, \mu \mathrm{V} / 10 \mathrm{~dB}$ & $-1.457 \pm 1.078$ \\
\hline Pretreatment $\mathrm{P} 2, \mu \mathrm{V} / 10 \mathrm{~dB}$ & $0.568 \pm 0.611$ \\
\hline Pretreatment $\mathrm{N} 1 / \mathrm{P} 2, \mu \mathrm{V} / 10 \mathrm{~dB}$ & $1.31 \pm 0.83$ \\
\hline Post-treatment $\mathrm{N} 1, \mu \mathrm{V} / 10 \mathrm{~dB}$ & $-0.904 \pm 0.812$ \\
\hline Post-treatment $\mathrm{P} 2, \mu \mathrm{V} / 10 \mathrm{~dB}$ & $0.606 \pm 0.591$ \\
\hline Post-treatment N1/P2, $\mu \mathrm{V} / 10 \mathrm{~dB}$ & $1.245 \pm 0.692$ \\
\hline \multicolumn{2}{|l|}{ LORETA* } \\
\hline Pretreatment N1 & $0.045 \pm 0.042$ \\
\hline Pretreatment P2 & $0.032 \pm 0.035$ \\
\hline Pretreatment N1/P2 & $0.038 \pm 0.038$ \\
\hline Post-treatment N1 & $0.035 \pm 0.028$ \\
\hline Post-treatment P2 & $0.023 \pm 0.021$ \\
\hline Post-treatment N1/P2 & $0.028 \pm 0.02302$ \\
\hline
\end{tabular}

$\mathrm{H} \& \mathrm{Y}=$ Hoehn and Yahr stage; LDAEP = loudness dependence of auditory evoked potentials; LED = levodopa equivalent dose; LORETA = low-resolution brain electromagnetic tomography; UPDRS $=$ Unified Parkinson's Disease Rating Scale.

Mean \pm standard deviation was presented

*Wilcoxon's signed ranks test.

Table 2: Comparison of demographic variables and LDAEP parameters between the early-onset and late-onset groups

\begin{tabular}{l|c|c|c}
\hline & $\begin{array}{c}\text { Early-onset group } \\
(\boldsymbol{n}=\mathbf{1 6})\end{array}$ & $\begin{array}{c}\text { Late-onset } \\
\text { group }(\boldsymbol{n}=\mathbf{1 4})\end{array}$ & $\boldsymbol{p}$ \\
\hline Age, years & $61.44 \pm 10.09$ & $77.36 \pm 3.71$ & $<0.001$ \\
\hline Age at onset, years & $59.00 \pm 9.77$ & $76.64 \pm 4.07$ & $<0.001$ \\
\hline Sex, males/females & $10 / 6$ & $10 / 4$ & 0.709 \\
\hline Modified H\&Y stage & $2.07 \pm 0.42$ & $2.43 \pm 0.62$ & 0.073 \\
\hline UPDRS & \multicolumn{3}{|l}{} \\
\hline I & $1.73 \pm 1.33$ & $2.45 \pm 4.03$ & 0.579 \\
\hline II & $7.73 \pm 4.61$ & $8.25 \pm 8.83$ & 0.846 \\
\hline III & $30.75 \pm 10.72$ & $33.14 \pm 15.84$ & 0.628 \\
\hline III (at 12 weeks) & $22.75 \pm 8.08$ & $23.77 \pm 11.61$ & 0.783 \\
\hline $\begin{array}{l}\text { LED, mg } \\
\text { (at 12 weeks) }\end{array}$ & $425.37 \pm 205.58$ & $449.04 \pm 140.36$ & 0.729 \\
\hline
\end{tabular}

Table 2: (Continued)

\begin{tabular}{c|c|c|c}
\hline & $\begin{array}{c}\text { Early-onset group } \\
(\boldsymbol{n}=\mathbf{1 6})\end{array}$ & $\begin{array}{c}\text { Late-onset } \\
\text { group }(\boldsymbol{n}=\mathbf{1 4})\end{array}$ & $\boldsymbol{p}$ \\
\hline $\begin{array}{c}\text { Levodopa, mg } \\
\text { (at 12 weeks) }\end{array}$ & $398.08 \pm 112.02$ & $438.16 \pm 143.11$ & 0.431 \\
\hline $\begin{array}{c}\text { Dopamine agonists } \\
\text { (at 12 weeks) }\end{array}$ & $\begin{array}{c}\text { Pramipexole: six } \\
\text { patients, ropinirole: } \\
\text { two patients }\end{array}$ & $\begin{array}{c}\text { Pramipexole: } \\
\text { one patient }\end{array}$ & 0.02 \\
\hline
\end{tabular}

Pretreatment LDAEP, $\mu \mathrm{V} / 10 \mathrm{~dB}$

\begin{tabular}{l|c|c|c}
\hline $\mathrm{N} 1$ & $-1.18 \pm 1.05$ & $-1.67 \pm 1.11$ & 0.227 \\
\hline $\mathrm{P} 2$ & $0.56 \pm 0.63$ & $0.57 \pm 0.59$ & 0.961 \\
\hline $\mathrm{N} 1 / \mathrm{P} 2$ & $0.99 \pm 0.68$ & $1.62 \pm 0.88$ & $0.035^{\dagger}$ \\
\hline
\end{tabular}

Post-treatment LDAEP, $\mu \mathrm{V} / 10 \mathrm{~dB}$

\begin{tabular}{l|c|c|c}
\hline $\mathrm{N} 1$ & $-0.61 \pm 0.61$ & $-1.26 \pm 0.91$ & $0.03^{\dagger}$ \\
\hline $\mathrm{P} 2$ & $0.61 \pm 0.66$ & $0.60 \pm 0.51$ & 0.97 \\
\hline $\mathrm{N} 1 / \mathrm{P} 2$ & $1.06 \pm 0.61$ & $1.46 \pm 0.74$ & 0.117 \\
\hline
\end{tabular}

Pretreatment LORETA*

\begin{tabular}{l|l|l|l}
\hline $\mathrm{N} 1$ & $0.04 \pm 0.05$ & $0.05 \pm 0.04$ & 0.561 \\
\hline $\mathrm{P} 2$ & $0.03 \pm 0.04$ & $0.03 \pm 0.02$ & 0.480 \\
\hline $\mathrm{N} 1 / \mathrm{P} 2$ & $0.04 \pm 0.04$ & $0.04 \pm 0.03$ & 0.533 \\
\hline
\end{tabular}

Post-treatment LORETA*

\begin{tabular}{l|l|l|l}
\hline $\mathrm{N} 1$ & $0.03 \pm 0.03$ & $0.04 \pm 0.02$ & 0.275 \\
\hline $\mathrm{P} 2$ & $0.02 \pm 0.02$ & $0.03 \pm 0.02$ & 0.231 \\
\hline $\mathrm{N} 1 / \mathrm{P} 2$ & $0.02 \pm 0.03$ & $0.03 \pm 0.02$ & 0.222 \\
\hline
\end{tabular}

$\mathrm{H} \& \mathrm{Y}=$ Hoehn and Yahr stage; LDAEP = loudness dependence of auditory evoked potentials; LED = levodopa equivalent dose; LORETA = low-resolution brain electromagnetic tomography; UPDRS $=$ Unified Parkinson's Disease Rating Scale.

Data are mean \pm standard deviation values.

*Mann-Whitney $U$-test.

${ }^{\dagger} p<0.05$.

Table 3: Multiple binary logistic regression analysis for early- and late-onset groups

\begin{tabular}{l|c|c|c|c|c}
\hline Variables & $\mathbf{C E}$ & $\mathbf{S E}$ & $\mathbf{d f}$ & $\mathbf{9 5 \%}$ C.I. & $\boldsymbol{p}$-value \\
\hline Intercept & -5.009 & 2.763 & 1 & $0.00002-1.500$ & 0.070 \\
\hline $\begin{array}{l}\text { Pretreatment N1/P2 } \\
\text { LDAEP }\end{array}$ & 1.204 & 0.599 & 1 & $1.031-10.784$ & $0.044 *$ \\
\hline Modified H\&Y stage & 1.578 & 1.107 & 1 & $0.553-42.454$ & 0.154 \\
\hline Sex & -0.361 & 0.968 & 1 & $0.104-4.652$ & 0.697 \\
\hline
\end{tabular}

$\mathrm{CE}=$ coefficient; $\mathrm{C}$.I. $=$ confidence interval; $\mathrm{df}=$ degree of freedom; $\mathrm{H} \& \mathrm{Y}=$ Hoehn and Yahr stage; LDAEP = loudness dependence of auditory evoked potentials; $\mathrm{SE}=$ standard error.

$* p<0.05$.

with $\mathrm{PD},{ }^{8}$ which is consistent with the finding of this study. The LDAEP was also significantly decreased by apomorphine, a dopamine agonist, in an animal study. ${ }^{10}$ These observations are associated with an increase of the serotonergic firing rate and release of serotonin in the raphe nuclei in the presence of dopamine agonists. ${ }^{26}$ However, since the serotonergic activity 
A

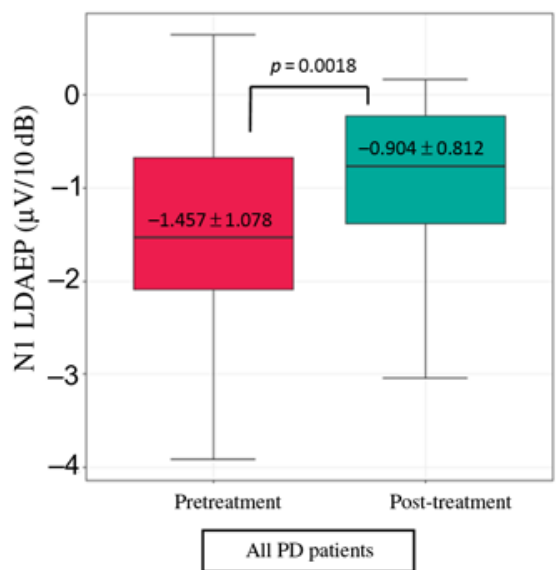

B

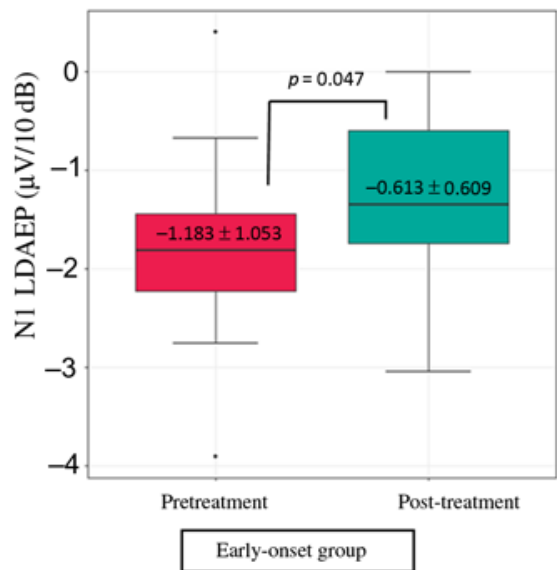

C

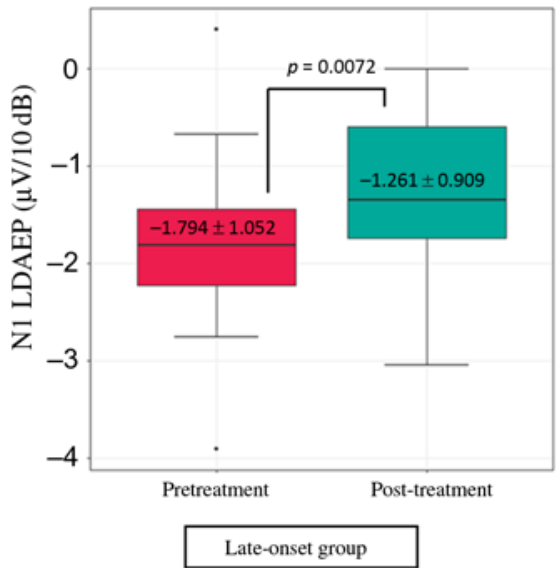

Figure 2: Change in the N1 LDAEP after 12 weeks of a dopaminergic medication. (A) Change in the N1 LDAEP in all 30 patients with PD. The absolute values of the N1 LDAEP in all patients decreased after 12 weeks of levodopa treatment $(\mathrm{p}=0.0018)$. (B) Change in the N1 LDAEP in the early-onset group. The absolute values of the N1 LDAEP in the early-onset patients decreased significantly after 12 weeks of levodopa treatment $(\mathrm{p}=0.047) .(C)$ Change in the N1 LDAEP in the late-onset group. The N1 LDAEP in the late-onset patients decreased significantly after 12 weeks of levodopa treatment $(\mathrm{p}=0.0072)$.

was measured after a relatively short period in both the previous study ${ }^{8}$ and the present study in PD, caution is required when concluding that alterations of serotonergic activity might occur with dopaminergic medications. In contrast to the findings of this study, Politis et al. ${ }^{4}$ reported that ${ }^{11} \mathrm{C}$-DASB binding was not correlated with dopaminergic medications. Furthermore, a review article by Stansley and Yamamoto ${ }^{27}$ reported that an increased level of dopamine could damage serotonergic neurons via oxidative stress, and that chronic levodopa treatment could lead to deficits in the serotonergic system. Further studies are needed to determine the relationships between the serotonergic system and dopaminergic therapy since the effect of dopaminergic therapy on serotonergic activity may be influenced by various factors. These include the extent of neuronal loss in the serotonergic system or dopaminergic system, the duration or dosage of dopaminergic medications, and the combined use of serotonergic medications.

The main strengths of this study are the inclusion of unmedicated subjects, the investigation of serotonergic activity according to the age of onset, and the repeated measurements of LDAEP. The inclusion of 30 patients with de novo PD in this study made it possible to assess central serotonergic activity during the early stages of PD. This study divided the patients into two groups according to age at onset, which could reveal whether the age at onset affects different serotonergic functions. Lastly, the LDAEP was measured twice, before and after 12 weeks of taking a dopaminergic medication, thereby allowing any changes in serotonergic functions according to the use of dopaminergic medications to be detected.

Some limitations of this study are worth mentioning. Normal controls were not included in this study, which means that the effects of age on the central serotonergic neurotransmission could not be determined. This might influence the results of this study: a younger age onset could have more preserved serotonergic activities. The age criteria between the early- and lateonset groups are arbitrary. We used the criteria by Mehanna et al., ${ }^{15}$ but the age criterion to classify groups according to the age of onset has been inconsistent. Although early-onset PD is more likely to be associated with LID, this study was not designed to evaluate LID since LDAEPs were examined in both unmedicated state and after 12 weeks of dopaminergic medications. Measuring the LDAEP does not assess the serotonin transporter or serotonin receptors but instead evaluates central serotonergic transmission in cortical areas. Thus, detailed information about the serotonergic system could not be obtained from the LDAEP measurements. However, these measurements are useful in clinical practice since they are both easy and inexpensive to perform. This study found that the serotonergic activity was higher in the early-onset PD patients and could be changed through dopaminergic therapy. Further studies are needed to confirm this finding.

\section{ACKNowledgements}

We appreciate all the participants in this study. In addition, we are thankful to Dr. Irene Litvan (Department of Neurosciences, Parkinson and other movement centers, UC San Diego, La Jolla, CA, USA) for her contribution in preparing this manuscript.

\section{Funding}

This research was supported by a grant from the National Research Foundation of Korea (NRF) funded by the Ministry of Education (grant number: NRF-2018R1D1A1A02085847) and a grant from Research year of Inje University in 2016 (20150897). This research was also supported by a grant of the Korea Health Technology R\&D Project through the Korea Health Industry Development Institute (KHIDI), funded by the Ministry of Health \& Welfare, Republic of Korea (grant number: HI18C0460).

\section{Disclosures}

HKP has received a grant of the Korea Health Technology R\&D Project through the Korea Health Industry Development Institute (KHIDI), funded by the Ministry of Health \& Welfare, Republic of Korea (grant number: HI18C0460).

J-JL declares no potential conflict of interest. 
Y-MP has received a grant from the National Research Foundation of Korea (NRF) funded by the Ministry of Education (grant number: NRF-2018R1D1A1A02085847) and a grant from Research year of Inje University in 2016 (20150897).

\section{Statement of Authorship}

HKP wrote the manuscript; J-JL and Y-MP reviewed and edited the manuscript.

\section{REFERENCES}

1. Politis M, Niccolini F. Serotonin in Parkinson's disease. Behav Brain Res. 2015;277:136-45.

2. Halliday GM, Blumbergs PC, Cotton RG, Blessing WW, Geffen LB. Loss of brainstem serotonin- and substance P-containing neurons in Parkinson's disease. Brain Res. 1990;510:104-7.

3. Braak H, Del Tredici K, Rub U, de Vos RA, Jansen Steur EN, Braak E. Staging of brain pathology related to sporadic Parkinson's disease. Neurobiol Aging. 2003;24:197-211.

4. Politis $\mathrm{M}, \mathrm{Wu} \mathrm{K}$, Loane $\mathrm{C}$, et al. Staging of serotonergic dysfunction in Parkinson's disease: an in vivo ${ }^{11} \mathrm{C}$-DASB PET study. Neurobiol Dis. 2010;40:216-21.

5. Pagano G, Niccolini F, Fusar-Poli P, Politis M. Serotonin transporter in Parkinson's disease: a meta-analysis of positron emission tomography studies. Ann Neurol. 2017;81:171-80.

6. Hegerl U, Gallinat J, Juckel G. Event-related potentials. Do they reflect central serotonergic neurotransmission and do they predict clinical response to serotonin agonists? J Affect Disord. 2001;62:93-100.

7. Lee KS, Park YM, Lee SH. Serotonergic dysfunction in patients with bipolar disorder assessed by the loudness dependence of the auditory evoked potential. Psychiatry Investig. 2012;9:298-306.

8. Beucke JC, Uhl I, Plotkin M, et al. Serotonergic neurotransmission in early Parkinson's disease: a pilot study to assess implications for depression in this disorder. World J Biol Psychiatry. 2010;11:781-7.

9. Juckel G. Serotonin: from sensory processing to schizophrenia using an electrophysiological method. Behav Brain Res. 2015; 277:121-4.

10. Juckel G, Molnár M, Hegerl U, Csépe V, Karmos G. Auditoryevoked potentials as indicator of brain serotonergic activity-first evidence in behaving cats. Biol Psychiatry. 1997;41:1181-95.

11. Park YM, Lee SH, Kim S, Bae SM. The loudness dependence of the auditory evoked potential (LDAEP) in schizophrenia, bipolar disorder, major depressive disorder, anxiety disorder, and healthy controls. Prog Neuro-Psychopharmacol Biol Psychiatry. 2010;34:313-6.

12. Wutzler A, Winter C, Kitzrow W, et al. Loudness dependence of auditory evoked potentials as indicator of central serotonergic neurotransmission: simultaneous electrophysiological recordings and in vivo microdialysis in the rat primary auditory cortex. Neuropsychopharmacology. 2008;33:3176-81.

13. Wickremaratchi MM, Ben-Shlomo Y, Morris HR. The effect of onset age on the clinical features of Parkinson's disease. Eur J Neurol. 2009;16:450-6.

14. Wickremaratchi MM, Knipe MD, Sastry BS, et al. The motor phenotype of Parkinson's disease in relation to age at onset. Mov Disord. 2011;26:457-63.

15. Mehanna R, Moore S, Hou JG, Sarwar AI, Lai EC. Comparing clinical features of young onset, middle onset and late onset Parkinson's disease. Parkinsonism Relat Disord. 2014;20: 530-4.

16. Björklund A, Kirik D, Carta M, Carlsson T. Dopamine released from 5-HT terminals is the cause of 1-DOPA-induced dyskinesia in parkinsonian rats. Brain. 2007;130:1819-33.

17. Gibb WR, Lees AJ. The relevance of the Lewy body to the pathogenesis of idiopathic Parkinson's disease. J Neurol Neurosurg Psychiatry. 1988;51:745-52.

18. Tomlinson CL, Stowe R, Patel S, Rick C, Gray R, Clarke CE. Systematic review of levodopa dose equivalency reporting in Parkinson's disease. Mov Disord. 2010;25:2649-53.

19. Fahn S, Elton RL, Members of the UPDRS Development Committee, editors. Unified Parkinson's disease rating scale. Florham Park, NJ: Macmillan Healthcare; 1987.

20. Lee BH, Park YM, Lee SH, Shim M. Prediction of long-term treatment response to selective serotonin reuptake inhibitors (SSRIs) using scalp and source loudness dependence of auditory evoked potentials (LDAEP) analysis in patients with major depressive disorder. Int J Mol Sci. 2015;16:6251-65.

21. RexSoft. Rex: Excel-based statistical analysis software. [online]. Available at: http://ressoft.org/.

22. Selikhova M, Williams DR, Kempster PA, Holton JL, Revesz T, Lees AJ. A clinico-pathological study of subtypes in Parkinson's disease. Brain. 2009;132:2947-57.

23. Diederich NJ, Moore CG, Leurgans SE, Chmura TA, Goetz CG. Parkinson disease with old-age onset: a comparative study with subjects with middle-age onset. Arch Neurol. 2003;60: 529-33.

24. Rylander D, Parent M, O'Sullivan SS, et al. Maladaptive plasticity of serotonin axon terminals in levodopa-induced dyskinesia. Ann Neurol. 2010;68:619-28.

25. Maillet A, Krack P, Lhommee E, et al. The prominent role of serotonergic degeneration in apathy, anxiety and depression in de novo Parkinson's disease. Brain. 2016;139:2486-502.

26. Kääriäinen TM, García-Horsman JA, Piltonen M, Huotari M, Männistö PT. Serotonergic activation after 2-week intrastriatal infusion of 1-Dopa and slow recovery of circling in rats with unilateral nigral lesions. Basic Clin Pharmacol Toxicol. 2008; 102:300-7.

27. Stansley BJ, Yamamoto BK. L-Dopa and brain serotonin system dysfunction. Toxics. 2015;3:75-88. 